\title{
A GEOGRAFIA NOS CURSOS DE PEDAGOGIA DAS IES PÚblicas do estado de SÃo PAUlo
}

\begin{tabular}{c}
\hline THE GEOGRAPHY IN PEDAGOGY COURSES OF PUBLIC HIGHER \\
EDUCATION INSTITUTES IN SÃO PAULO STATE \\
\hline LA GEOGRAFÍA EN LOS CURSOS DE PEDAGOGÍA DE LAS \\
UNIVERSIDADES PÚBLICAS DEL ESTADO DE SÃO PAULO EN BRASIL
\end{tabular}

\author{
Thais Angela Cavalheiro Azevedo ${ }^{1}$ \\ Andrea Coelho Lastória ${ }^{2}$ \\ Filomena Elaine Paiva Assolini ${ }^{3}$
}

\begin{abstract}
RESUMO: Os professores dos anos iniciais do Ensino Fundamental devem ser, prioritariamente, Licenciados em Pedagogia. Nessa etapa da escolarização, uma das áreas do conhecimento que devem ser contempladas é a Geografia. Assim, no presente artigo temos como objetivo identificar como os componentes curriculares voltados para o ensino de Geografia são propostos nos currículos formais dos cursos de Licenciatura em Pedagogia. Realizamos um trabalho com contornos qualitativos, por meio de análise documental envolvendo nove cursos na modalidade presencial em instituições públicas paulistas. Constatamos que as cargas horárias apresentam considerável variedade entre os cursos. A Geografia está presente quando são propostos os estágios supervisionados, as linhas de pesquisa, entre outras práticas. As Licenciaturas em Pedagogia contemplam o ensino de Geografia, de diferentes maneiras e com variadas denominações, portanto, seu "lugar" é garantido, mesmo que minimante, no currículo da formação docente.
\end{abstract}

PalavraS-Chave: Curso de pedagogia. Currículo. Ensino de geografia.

ABSTRACT: The teachers of the first years of Elementary Education should be, as a matter of priority, graduated in Pedagogy. At this stage of schooling, one of the subjects of knowledge that must be considered is Geography. This article aims to identify how the geography teaching curricular components are proposed in the formal curriculum of the undergraduation courses of Pedagogy. We performed a qualitative investigation, through document analysis involving nine courses in face-to-face mode of public institutions in São Paulo. We verified that the workloads of the institutions present a considerable variety among them. Geography is present in supervised internships, research lines, and other practices. The courses of Pedagogy include the teaching of Geography, in different ways and with different denominations, therefore, its "place" is guaranteed, even if minimally, in the curriculum of the teachers' training.

KEYWORDS: Pedagogy course. Curriculum. Geography teaching.

RESUMÉN: Los professores de los años iniciales de la ensenãnza fundamental deben ser prioritariamente licenciados en Pedagogía. En esta etapa de escolaridade, una de las áreas del conocimiento que deben tenerse en cuenta es la Geografía. En este artículo tenemos como objetivo identificar como los componentes curriculares destinados para la enseñanza de la Geografía son propuestos en los currículos formales de los cursos de Pedagogía. Realizamos um trabajo cualitativo, a través de documentos que involucran nueve cursos en la modalidade presencial en las insticiones públicas paulistas. Podemos comprobrar que el horário presenta una variedad entre los cursos. La Geografía está presente cuando son propuestas las prácticas supervisadas, las líneas

Submetido em: 30/10/2017 - Aceito em: 26/11/2017 - Publicado em: 14/02/2018.

\begin{tabular}{l|c|c|c|c|c|c} 
(C) Rev. Educ. Perspec. & Viçosa, $M G$ & v. & n.3 & p.462-477 & set./dez. 2017 & eISSN 2178-8359 \\
\hline
\end{tabular}


de estúdio, sobre otros ejercicios. Los cursos de Pedagogía abarcan la enseñanza de Geografía, de distintas maneras y con variadas denominaciones, así su "lugar" es garantizado, incluso cuando minimamente, en el currículo de la formación docente.

PALABRAS CLAVE: Cursos de pedagogía. Currículo. Enseñanza de la geografía.

\section{INTRODUÇÃO}

O presente artigo apresenta parte de uma investigação de mestrado, realizada no ano de 2016, junto ao Programa de Pós-Graduação em Educação da Faculdade de Filosofia, Ciências e Letras de Ribeirão Preto, na Universidade de São Paulo. Abordamos aspectos relacionados aos cursos de Licenciatura em Pedagogia, mais precisamente refletimos a respeito do "lugar" da Geografia em tais licenciaturas. Salientamos que no Brasil, o profissional que atua como professor nos anos iniciais do Ensino Fundamental deve ser, prioritariamente ${ }^{\mathrm{i}}$, licenciado em pedagogia.

Os pedagogos são profissionais que atuarão contemplando diversas áreas do conhecimento, dentre elas: Artes, Ciências, Geografia, História, Língua Portuguesa e Matemática. Nesse contexto, consideramos que, a variedade de componentes curriculares, provenientes das distintas áreas do conhecimento, impõe ao pedagogo um complexo trabalho educativo. $\mathrm{O}$ trabalho do pedagogo unirá os conhecimentos teóricos e práticos. Por essa razão, a formação docente deverá também refletir essa necessária associação entre teoria e prática, preparando os professores para desenvolver "uma atividade prática que é sempre teórica, pensada, e um movimento do pensamento, do que resulta uma prática pensada", tal como preconizou Libâneo (2012, p. 55). Para o desenvolvimento de práticas planejadas, pensadas e reflexivas o professor precisará contar com uma formação inicial e continuada que aponte para esse propósito.

O profissional formado de acordo com tais concepções, poderá desenvolver práticas que contemplem a Geografia de forma contextualizada e significativa, contribuindo para que o estudante construa sua leitura e interpretação do mundo. Nesse sentido, os Parâmetros Curriculares Nacionais (PCNs) valorizam o ensino de Geografia, ressaltando-o como essencial para o desenvolvimento de uma educação cidadã.

A Geografia é uma área de conhecimento comprometida em tornar o mundo compreensível para os alunos, explicável e passível de transformações. Neste sentido, assume grande relevância dentro do contexto dos Parâmetros Curriculares Nacionais, em sua meta de buscar um ensino para a conquista da cidadania (BRASIL, 1997, p. 26).

A educação cidadã é um dos principais objetivos do ensino de Geografia nos anos iniciais do Ensino Fundamental. Além da construção da cidadania os conhecimentos geográficos

\begin{tabular}{l|l|l|l|l|l|l} 
(C) Rev. Educ. Perspec. & Viçosa, $M G$ & v. & n.3 & p.462-477 & set./dez. 2017 & eISSN 2178-8359 \\
\hline
\end{tabular}


colaboram para a construção da leitura e compreensão do mundo. Segundo Callai (2005, p. 37) é:

Por meio da geografia, nas aulas dos anos iniciais do ensino fundamental, que podemos encontrar uma maneira interessante de conhecer o mundo, de nos reconhecermos como cidadãos e de sermos agentes atuantes na construção do espaço em que vivemos. $\mathrm{E}$ os nossos alunos precisam aprender a fazer as análises geográficas. E conhecer o seu mundo, o lugar em que vivem, para poder compreender o que são os processos de exclusão social e a seletividade dos espaços.

Tendo em vista tal compreensão, o ensino de Geografia aponta para a formação de um aluno autor, autônomo e reflexivo, pois como afirmam Pontuschka, Paganelli e Cacete (2009, p. 38) "a Geografia, como disciplina escolar, oferece sua contribuição para que alunos e professores enriqueçam suas representações sociais e seu conhecimento sobre as múltiplas dimensões da realidade social, natural e histórica, entendendo melhor o mundo". Consideramos que a leitura e compreensão do mundo caminham juntas com a reflexão sobre a realidade vivida pelo estudante, uma vez que, "a Geografia necessariamente, deve proporcionar a construção de conceitos que possibilitem ao aluno compreender o seu presente e pensar o futuro com responsabilidade, ou ainda, preocupar-se com o futuro através do inconformismo com o presente" (STRAFORINI, 2004, p. 151).

Deste modo, as práticas educativas reflexivas e voltadas para o ensino de Geografia precisam estar alinhadas a uma formação docente que contemple tais aspectos. Ante o exposto, desenvolvemos uma investigação que teve como foco estudar o "lugar" do ensino de Geografia nos cursos de Licenciatura em Pedagogia. Tal investigação teve como objetivo central identificar como os componentes curriculares, voltados para o ensino de Geografia, são propostos no currículo formal, dos cursos de Licenciatura em Pedagogia (presenciais) das universidades públicas paulistas. Os objetivos específicos da nossa investigação foram: i) Analisar os Projetos Político Pedagógicos (PPP) dos cursos de Licenciatura em Pedagogia das universidades selecionadas, considerando os aspectos referentes ao ensino de Geografia; ii) Identificar como as metodologias de ensino são tratadas nas propostas curriculares e identificar o "lugar" da Geografia nesse contexto; iii) Analisar as ementas dos componentes curriculares que envolvem o ensino de Geografia, reconhecendo as variações de suas nomenclaturas, cargas horárias, os temas mais abordados, dentre outros.

\section{O DESENVOLVIMENTO METODOLÓGICO}

Para refletir a respeito do nosso percurso metodológico dialogamos com as autoras Lüdke e André (1986) que apontam a natureza das indagações como fator determinante para a escolha metodológica da pesquisa. Tendo em vista tal afirmativa apresentamos as questões centrais desta investigação: Será que o "lugar" da Geografia está "assegurado" nos currículos dos

\begin{tabular}{l|c|c|c|c|c|c} 
() Rev. Educ. Perspec. & Viçosa, $M G$ & v. & n.3 & p.462-477 & set./dez. 2017 & eISSN 2178-8359 \\
\hline
\end{tabular}


cursos de Pedagogia das Instituições de Educação Superior (IES) públicas estaduais paulistas? Se sim, qual é esse lugar?

Com o propósito de responder tais questões realizamos uma investigação qualitativa de caráter documental. Dessa forma contemplamos o nível formal do currículo, das IES públicas estaduais paulistas. A análise documental é uma fonte significativa para a leitura da realidade, pois os dados obtidos surgem de forma contextualizada e fornecem informações relevantes. Lüdke e André (1986, p. 39) caracterizam os "documentos" no contexto da pesquisa educacional como

uma fonte poderosa de onde podem ser retiradas evidências que fundamentam afirmações e declarações do pesquisador. Representam ainda uma fonte "natural" de informação. Não são apenas uma fonte de informação contextualizada, mas surgem num determinado contexto e fornecem informações sobre esse mesmo contexto.

Os principais documentos analisados foram os Projetos Políticos Pedagógicos (PPPs) das IES estudadas. O PPP é uma referência basilar para o planejamento, desenvolvimento e avaliação dos cursos de Pedagogia, por isso o reputamos como uma importante fonte nessa investigação documental. Outros importantes documentos estudados foram os programas de ensino dos componentes curriculares voltados para o ensino de Geografia, vigentes no ano de 2016, nos cursos de Licenciatura Plena em Pedagogia.

Tais documentos estão diretamente relacionados ao currículo oficial das Instituições de Educação Superior. As reflexões sobre currículo envolvem fatores políticos, econômicos, sociais, culturais e educacionais, pois como afirma Sacristán (1998, p. 61), o currículo: "é expressão do equilíbrio de interesses e forças que gravitam sobre o sistema educativo num dado momento, enquanto que através dele se realizam os fins da educação no ensino escolarizado". Ao utilizarmos documentos curriculares educacionais em nossa investigação lidamos com os aspectos citados pelo autor, além de termos que levar em conta as circunstâncias históricas e políticas em que os documentos foram elaborados.

Os documentos analisados ${ }^{\mathrm{ii}}$ pertencem a nove cursos de Licenciatura Plena em Pedagogia na modalidade presencial de ensino de IES estaduais do estado de São Paulo, as instituições pesquisadas foram: Faculdade de Educação - Universidade Estadual de Campinas (UNICAMP) (2015), Faculdade de Educação - Universidade de São Paulo (USP) (2012), Faculdade de Filosofia Ciências e Letras de Ribeirão Preto - USP (2013), Faculdade de Ciências - Universidade Estadual Paulista (UNESP) de Bauru (2006), Instituto de Biociências, Letras e Ciências Exatas - UNESP/São José do Rio Preto (2008), Faculdade de Ciências e Letras de Araraquara. - UNESP/Araraquara (2015), Instituto de Biociências UNESP/Rio Claro (2011), Faculdade de Ciências e Tecnologia - UNESP/Presidente Prudente (2011), Faculdade de Filosofia e Ciências - UNESP/Marília (2007).

\begin{tabular}{l|c|c|c|c|c|c} 
() Rev. Educ. Perspec. & Viçosa, $M G$ & v. & n.3 & p.462-477 & set./dez. 2017 & eISSN 2178-8359 \\
\hline
\end{tabular}


Com a leitura e análise dos documentos citados anteriormente encontramos: as denominações das disciplinas obrigatórias que envolvem diretamente o ensino de Geografia; as respectivas cargas horárias; denominações e cargas horárias das disciplinas optativas que envolvem o ensino de Geografia, dentre outras informações.

De posse dos documentos necessários, procedemos à análise dos PPPs e dos programas de ensino, dos componentes curriculares voltados para o ensino de Geografia. Investigamos os dados obtidos com o propósito de levantar respostas e indícios para as questões da pesquisa e refletir sobre a presença do ensino de Geografia na formação do pedagogo.

\section{A PRESENÇA DA GEOGRAFIA NOS CURSOS DE PEDAGOGIA}

Para investigar a presença da Geografia nos cursos de Licenciatura em Pedagogia, um dos aspectos que analisamos foi a carga horária destinada aos componentes curriculares voltados a esta área do conhecimento. Consideramos que o tempo atribuído pelos cursos para o trabalho com as noções e conceitos geográficos é uma informação relevante para a compreensão do "lugar" ocupado pela Geografia nos referidos cursos. Com tais informações elaboramos o gráfico 1, cujo título é "Cargas horárias dos componentes curriculares voltados para o ensino de Geografia”.

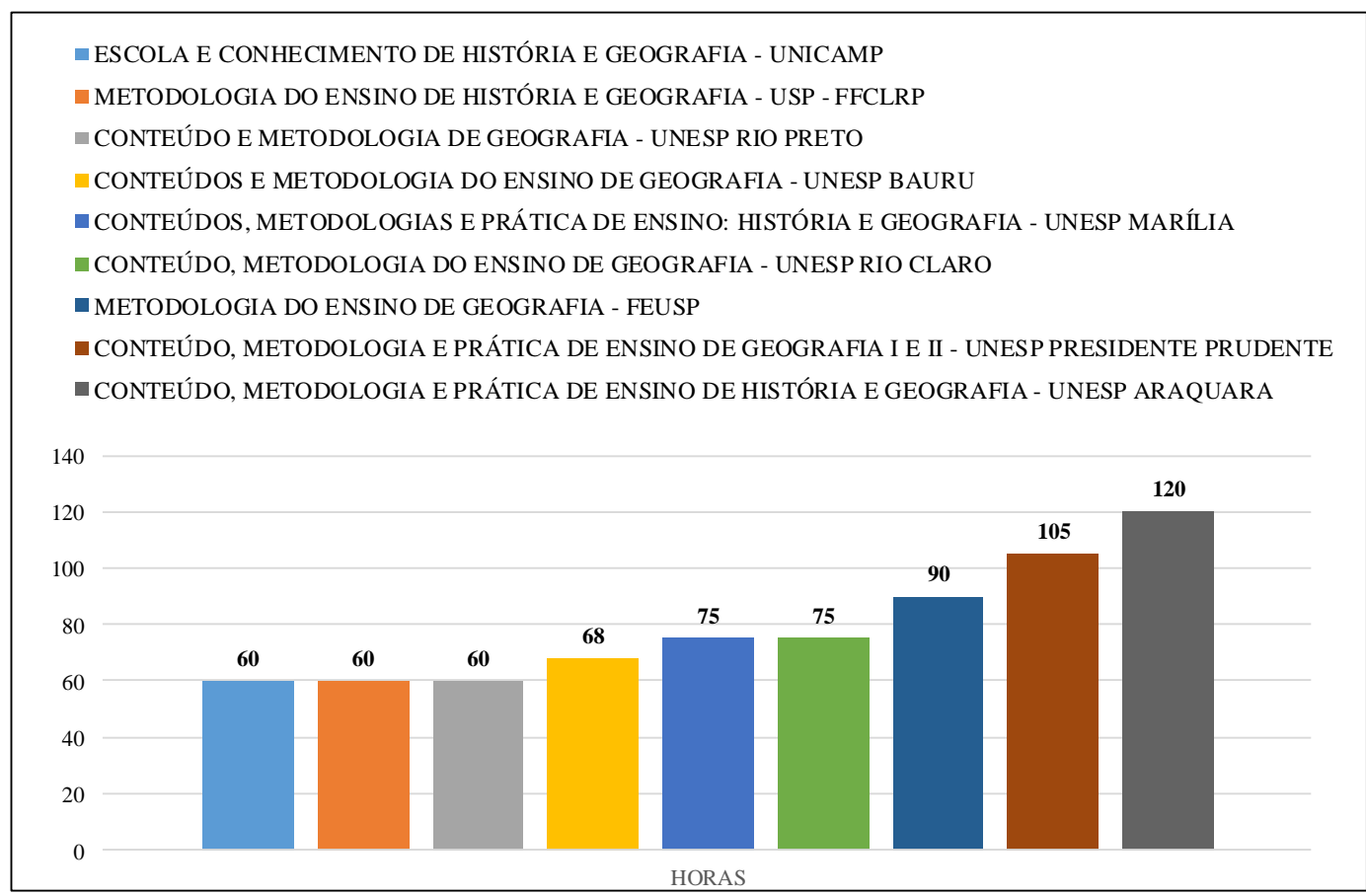

Gráfico 1. Cargas horárias dos componentes curriculares voltados ao ensino de geografia Fonte: PPPs das IES investigadas

\begin{tabular}{l|l|l|l|l|l|l} 
(C) Rev. Educ. Perspec. & Viçosa, $M G$ & v. & n.3 & p.462-477 & set./dez. 2017 & eISSN 2178-8359 \\
\hline
\end{tabular}


Ao analisarmos as cargas horárias dos componentes curriculares voltados para o ensino de Geografia nos deparamos com uma variedade considerável entre os cursos estudados. A menor carga apresentada foi de 60 horas (divididas entre História e Geografia), na Faculdade de Filosofia, Ciências e Letras de Ribeirão Preto da USP e na Faculdade de Educação da UNICAMP. A maior foi de 105 horas na UNESP de Presidente Prudente, destinadas exclusivamente para Geografia.

Em alguns dos componentes curriculares estudados detectamos que as áreas de História e Geografia se encontram reunidas. Dentre os nove cursos de Pedagogia investigados, quatro apresentam componentes curriculares que reúnem as áreas de História e Geografia. Partilhamos da ideia que, o ensino da Geografia e o da História, são intimamente ligados. Relacionar os conhecimentos geográficos aos históricos pode enriquecer a prática educativa e torná-la mais contextualizada. Entendemos tal ação como interdisciplinar, e concordamos com Garruti e Santos (2004, p. 66), que apontam a interdisciplinaridade "como uma forma de superar a visão fragmentada da produção de conhecimento e de articular as inúmeras partes que compõem os conhecimentos da humanidade".

O diálogo entre as áreas do conhecimento é um aspecto central para a construção da interdisciplinaridade. Esta concepção de interdisciplinaridade em que o diálogo entre as áreas do conhecimento tem papel de destaque e que pretende desenvolver o conhecimento de maneira mais ampla se contrapõe à proposta que apenas divide o tempo das aulas entre os conteúdos específicos, da qual não somos partidárias.

Tendo em vista os aspectos da interdisciplinaridade, apresentamos a afirmação das autoras Pontuschka, Paganelli e Cacete (2009, p. 173) que destacam o estudo do meio como: "uma metodologia de ensino interdisciplinar que pretende desvendar a complexidade de um espaço determinado extremamente dinâmico e em constante transformação". Concordamos com as autoras pois, compreendemos o estudo do meio como uma possibilidade para a construção de reflexões interdisciplinares a respeito das relações que envolvem a natureza e a sociedade, de forma contextualizada e dinâmica.

Tais atividades foram apresentadas com diferentes denominações nos documentos analisados, por exemplo, excursões didáticas, aulas passeio e estudos do meio. Dentre as nove IES estudadas, quatro delas citam estas ações em seus programas de ensino, são elas: a UNESP de Bauru (2006) que expõe que desenvolverá "aula-passeio". A UNESP de Marília (2007) explicita que pretende trabalhar com "atividades extra-classe". Outra instituição que inclui, em suas estratégias, atividades em outros contextos, é a UNESP de Rio Claro (2011), que menciona "aulas práticas em laboratório". E por fim, temos a UNESP de Presidente Prudente (2011) que cita, como uma de suas estratégias, a atividade de "estudos do meio".

\begin{tabular}{l|c|c|c|c|c|c} 
() Rev. Educ. Perspec. & Viçosa, $M G$ & v. & n.3 & p.462-477 & set./dez. 2017 & eISSN 2178-8359 \\
\hline
\end{tabular}


As estratégias de ensino presentes nos componentes curriculares voltados ao ensino de Geografia

Além de encontrarmos a presença do "estudo do meio", analisamos também a presença de demais estratégias de ensino presentes nos programas de ensino dos componentes curriculares voltados para o ensino de Geografia. Dentre as estratégias encontradas podemos citar: leituras, discussões, oficinas, aulas expositivas teóricas e/ou dialogadas, atividades práticas, seminários, apresentação e elaboração de filmes, atividades escritas, construção de mapas, orientação para o planejamento de práticas, excursões didáticas, pesquisas sistematizadas, trabalhos em grupo e a confecção e exposição de materiais didáticos.

Essa informação nos indica que o graduando em Pedagogia terá a oportunidade de envolverse com o conteúdo de várias maneiras. Valorizamos esta característica, assim como Stacciarini e Esperidião (1999, p. 65) que afirmam que "o uso de estratégias de ensino variadas, [...] propiciam a melhor assimilação do conteúdo programático”.

A utilização de variadas estratégias de ensino presente nos componentes curriculares voltados para o ensino de Geografia demonstra a intenção de superar estratégias tradicionais e mecanizadas na Geografia. A autora Cavalcanti (1998, p. 132) expõe a problemática envolvida na manutenção de estratégias mecanizadas na educação geográfica:

A memorização induzida na geografia não é uma memorização desejada pelo aluno, pode-se dizer mesmo que é uma memorização forçada. $\mathrm{O}$ aluno, em geral, não quer decorar fatos, nomes da geografia, não porque ele não quer decorar nenhuma informação, mas porque ele não é mobilizado para as informações da geografia.

Para que a Geografia Escolar supere os processos educacionais mecanizados e de memorização, precisamos transformar as concepções teórico-metodológicas. Tais transformações necessitam ser voltadas para a construção coletiva do conhecimento e para a leitura de mundo. A respeito de tal superação Callai (2005, p. 231) explicita que

\footnotetext{
Para romper com a prática tradicional da sala de aula, não adianta apenas a vontade do professor. É preciso que haja concepções teórico metodológicas capazes de permitir o reconhecimento do saber do outro, a capacidade de ler o mundo da vida e reconhecer a sua dinamicidade, superando o que está posto como verdade absoluta. É preciso trabalhar com a possibilidade de encontrar formas de compreender o mundo, produzindo um conhecimento que é legítimo.
}

Por meio da Educação geográfica podemos construir concepções de ensino mais amplas, complexas e significativas para os educandos. É essencial que as estratégias e procedimentos educacionais voltem-se para a reconstrução dos conteúdos, de forma inovadora, assim, como afirma Guimarães $(2009$, p. 327) é por meio de "uma prática criativa com as diferentes linguagens, que o professor pode contribuir para que o aluno se aproprie de bens culturais essenciais para a sua formação. Esse é um dever da escola e particularmente, dos professores

\begin{tabular}{l|c|c|c|c|c|c} 
() Rev. Educ. Perspec. & Viçosa, $M G$ & v. & n.3 & p.462-477 & set./dez. 2017 & eISSN 2178-8359 \\
\hline
\end{tabular}


de Geografia”. A utilização de diferentes linguagens, no desenvolvimento das práticas educativas, voltadas para o ensino de Geografia, também é valorizada pela autora Castellar (2011, p. 123), quando afirma que "a possibilidade de utilizar diferentes linguagens proporciona aos alunos meios para compreender os fenômenos do espaço geográfico”. A respeito das diferentes linguagens, destacamos a linguagem cartográfica.

\section{A Linguagem Cartográfica nos cursos de Pedagogia}

Na presente investigação, identificamos a Cartografia Escolar no currículo de todos os cursos estudados. Consideramos a presença da linguagem cartográfica muito importante nos cursos de Pedagogia, pois defendemos o trabalho com a Cartografia Escolar desde os primeiros anos da escolarização. O desenvolvimento desta linguagem possibilita a leitura e a interpretação do espaço próximo ou distante por meio de símbolos que se inter-relacionam, representando no papel um espaço reduzido, que oferece ao leitor informações que o ajudarão a se localizar. Esta temática deve ser trabalhada desde os anos iniciais do ensino fundamental, por meio de jogos e brincadeiras (MARTINELLI, 1998).

Para que a linguagem cartográfica seja desenvolvida, na Educação Infantil e nos anos iniciais do Ensino Fundamental, é necessário que os docentes que atuarão nessas etapas da escolarização a conheçam e saibam a relevância de contemplá-la nas práticas educativas.

Os Parâmetros Curriculares Nacionais de Geografia para os anos iniciais do Ensino Fundamental (BRASIL, 1997) explicitam que a alfabetização cartográfica compreende uma série de aprendizagens que podem ser desenvolvidas desde os anos iniciais da Educação Básica. De acordo com o documento, tais aprendizagens devem conduzir o trabalho com as representações cartográficas e sua linguagem específica. Para tal desenvolvimento é recomendado o uso de imagens e fotografias, que tenham significado e despertem o interesse da criança e façam parte do seu cotidiano.

O trabalho com a Cartografia Escolar pode ser um meio de voltar-se para a localidade do estudante, por exemplo, em uma proposta de oficina de mapas do bairro. Com o desenvolvimento desta oficina, diversas reflexões poderão ser construídas, como as que envolvem o tema da coleta seletiva, da arborização, dos rios que perpassam o bairro, dentre outras. Segundo Almeida e Passini (1999, p. 14) o processo de aquisição da linguagem cartográfica é um "meio de se instrumentalizar o sujeito para desvendar o mundo". Consideramos a Cartografia Escolar como uma linguagem, não apenas como uma técnica ou conteúdo específico. Nesse sentido Cavalcanti (2010, p. 9) aponta que "no processo de alfabetização cartográfica, a cartografia aparece não apenas como técnica ou tópico de conteúdo, mas como linguagem, com códigos, símbolos e signos. Essa linguagem precisa ser aprendida pelo aluno para que ele possa se inserir no processo de comunicação".

\begin{tabular}{l|c|c|c|c|c|c} 
() Rev. Educ. Perspec. & Viçosa, $M G$ & v. & n.3 & p.462-477 & set./dez. 2017 & eISSN 2178-8359 \\
\hline
\end{tabular}


Valorizamos a presença da Cartografia Escolar nos cursos de Pedagogia, pois a Linguagem Cartográfica pode colaborar com a construção de práticas educativas em que o estudante compreenda a realidade de maneira ampla e em suas múltiplas dimensões, como a ambiental, política e socioeconômica.

\section{Os conceitos geográficos como instrumentos para a leitura do mundo}

Nos componentes curriculares voltados ao ensino de Geografia identificamos, também, o trabalho com os conceitos geográficos. Selecionamos alguns trechos do planejamento curricular que demonstrou tal presença.

O programa de ensino do componente curricular "Conteúdos e Metodologias do Ensino de Geografia” da UNESP de Bauru (2006, p. 2) afirma que estudará "a definição de conteúdos procedimentais e valorativos para a orientação das ações, atitudes e comportamentos sócio espaciais; Os conceitos geográficos como instrumentos básicos para a leitura do mundo do ponto de vista geográfico".

Fica evidente que o componente curricular pretende trabalhar com os conceitos geográficos e os coloca como instrumentos para a leitura do mundo. Tal aspecto possibilita-nos entender que o intuito de formar professores que possam desenvolver práticas voltadas à leitura e compreensão do mundo está presente nessa instituição de ensino. Sobre o referido processo de leitura e compreensão do mundo, Lampert (2013, p. 133) explicita que "compreender o mundo vai além de memorizar os nomes de seus Estados e nações [...], significa entender nosso cotidiano e enxergar a si próprio como agente de transformação das paisagens e do espaço geográfico".

Os conceitos geográficos são apontamos como um dos alicerces para a formação de professores também no componente curricular "Metodologia do Ensino de História e Geografia" da Faculdade de Filosofia, Ciências e Letras de Ribeirão Preto da USP (2013, p. 1) que expõe como alguns de seus objetivos contribuir para que os estudantes sejam capazes de "compreender o Ensino de História e Geografia como essenciais para o processo de Educação para a Cidadania; Reconhecer as principais categorias teóricas da Geografia e da História Escolar; Conhecer, inter-relacionar e compreender a organização do espaço geográfico".

Assim como no trecho destacado da Faculdade de Filosofia, Ciências e Letras de Ribeirão Preto da USP, encontramos no componente curricular "Metodologia do Ensino de Geografia" da Faculdade de Educação da USP (2012, p. 1) a intencionalidade de realizar estudos que envolvam os conceitos geográficos, por exemplo, no ponto em que diz: "O curso promove o

\begin{tabular}{l|c|c|c|c|c|c} 
(c) Rev. Educ. Perspec. & Viçosa, $M G$ & v. & n.3 & p.462-477 & set./dez. 2017 & eISSN 2178-8359 \\
\hline
\end{tabular}


estudo dos autores que descreveram e interpretaram os conceitos geográficos relacionando-os com o cotidiano e o processo de aprendizagem".

Nesses trechos, observamos que os componentes curriculares, pretendem construir junto ao estudante de Licenciatura em Pedagogia a noção de que os conhecimentos geográficos podem colaborar para a leitura de mundo. Segundo Callai (2005, p. 228) a construção da leitura do mundo, pode ser considerada como o papel central da Geografia na escola.

Ler o mundo da vida, ler o espaço e compreender que as paisagens que podemos ver são resultado da vida em sociedade, dos homens na busca da sua sobrevivência e da satisfação das suas necessidades. Em linhas gerais, esse é o papel da geografia na escola. Refletir sobre as possibilidades que representa, no processo de alfabetização, o ensino de geografia, passa a ser importante para quem quer pensar, entender e propor a geografia como um componente curricular significativo.

Para que o ensino de Geografia seja desenvolvido de modo significativo nos anos iniciais do Ensino Fundamental salientamos que é essencial que as práticas educativas sejam realizadas de forma singular e voltadas para a localidade do educando, colaborando com a construção da leitura de mundo e com a reflexão sobre a realidade que o cerca, pois assim como afirma Almeida (1991, p. 34) "o aluno deve partir da identificação dos elementos observados, assim poderá, depois, questionar a ocorrência desses elementos em sua localidade". Com isso, ressaltamos que é fundamental que o trabalho com a Localidade esteja presente nos cursos de formação de professores.

\section{A valorização da Localidade nos cursos de formação de professores}

Para que os docentes dos anos iniciais desenvolvam o planejamento e o desenvolvimento de práticas educativas voltadas para a Localidade, é necessário que sua formação proporcione subsídios para tal. Valorizamos o desenvolvimento de práticas que contemplem a localidade do aluno, por acreditarmos que com isso, os estudantes poderão construir identidade e pertencimento com seu local de vivência. Corroborando com essa premissa Lampert (2013, p. 136) ressalta que "a partir do estudo dos elementos do lugar onde se localiza a escola é possível que os alunos tenham elementos para construir sua identidade e pertencimento".

As práticas educativas voltadas à construção do sentimento de identidade e pertencimento estão diretamente relacionadas à cidadania, pois, conhecendo os elementos do local, o estudante poderá refletir sobre o seu entorno e construir propostas inovadoras. Nesse sentido Lastória e Mello (2008, p. 5) apontam que

O cotidiano deve ser percebido como uma ferramenta poderosa a ser utilizada pelo professor, uma dentre tantas que detêm qualidades específicas. No dia-a-dia da sala de aula, ele se revela uma peça fundamental para a construção do cidadão que estuda História e Geografia. 
Considerando a relevância do trabalho com a localidade e cotidiano do estudante, observamos os programas de ensino, dos componentes curriculares voltados para o ensino de Geografia e selecionamos alguns trechos. A Faculdade de Educação da USP (2012, p. 1) explicita em sua ementa que "O curso promove o estudo dos autores que descreveram e interpretaram os conceitos geográficos relacionando-os com o cotidiano e o processo de aprendizagem" Na UNESP de São José do Rio Preto (2008, p. 1), este aspecto aparece relacionado à utilização de uma metodologia inovadora, pois o componente curricular diz que pretende trabalhar "por meio da produção de curtas metragens associados ao local, ao presente e ao cotidiano do aluno".

Consideramos que ao incluirmos estudos sobre a localidade, o cotidiano e as suas relações, estamos colaborando para uma formação voltada para a leitura de mundo, pois, como aponta Callai (2011, p. 37) "ler o mundo significa compreender e estabelecer relações entre o espaço local, o lugar, o território e o espaço global”.

Nos conteúdos programáticos da Faculdade de Filosofia, Ciências e Letras de Ribeirão Preto - USP (2013, p. 2) encontramos referências ao estudo do local e do cotidiano, no trecho que propõe como um dos seus eixos o estudo do "cotidiano e a localidade no ensino de Geografia e História". E também nos conteúdos trabalhados na UNESP de Rio Claro (2011, p. 1), que tem como um dos seus itens o trabalho com o "Cotidiano e conhecimento geográfico". A presença desses aspectos nos conteúdos programáticos dos componentes curriculares voltados para o ensino da Geografia é por nós valorizado, pois acreditamos que, se o professor em formação constrói reflexões em torno dos estudos da localidade e do cotidiano, poderá contemplar em suas ações educativas tais itens também

Com isso, as práticas educativas podem se tornar mais contextualizadas, afinal, concordando com Oliveira (2011, p. 16) "além do conhecimento e aspectos profissionais da docência, acreditamos que no processo de ensino e formação docente é importante considerar a localidade". O autor ressalta a importância do trabalho com a localidade durante o curso de Licenciatura Plena em Pedagogia e também aponta que os aspectos profissionais da docência devem ser trabalhados. Buscamos em nossa investigação tais aspectos por meio da presença de estágios supervisionados.

\section{Estágios Supervisionados e a pesquisa educacional durante o curso de Pedagogia}

Ao analisarmos os PPPs, em seu texto na íntegra, encontramos em todos os cursos investigados a Geografia como uma possibilidade para o desenvolvimento de práticas de estágio. Por exemplo, o documento da USP de Ribeirão Preto (2013, p. 21) descreve que

Os componentes curriculares da disciplina-estágio Ação Pedagógica Integrada Ensino Fundamental II referem-se ao ensino de História, Geografia e Ciências. [...] 
A proposta de estágio tem também cunho investigativo e propositivo, culminando com a produção de relatórios finais.

A respeito do processo de estágio, concordamos com as autoras Silva e Lastória (2013, p. 88) que defendem a ideia de que "para aprender a ensinar é preciso desenvolver a prática pedagógica, ou melhor, é fundamental aprender pela experiência que o estágio pode propiciar nos processos de formação inicial”.

Compartilhamos da ideia de que os estágios supervisionados na formação do pedagogo não são apenas uma mera apropriação do caráter prático, mas sim, um momento de reflexão crítica e intervenção na realidade. A respeito dos estágios supervisionados Pimenta e Lima (2011, p. 16) afirmam que, tal atividade "pode permitir a compreensão e problematização das situações educacionais observadas".

Acrescentamos, ainda, que a investigação educacional e os estágios supervisionados, podem estar unidos. A atividade de estágio pode desenvolver a postura e as habilidades de pesquisador, por meio da elaboração de projetos, que lhe permitam refletir sobre as situações que observam (PIMENTA; LIMA, 2011).

Ao analisarmos a inserção da Geografia nos PPPs, encontramos, também, possibilidades para os pedagogos em formação realizarem atividades de pesquisa na referida área do conhecimento. O documento da UNESP de Presidente Prudente (2011, p. 22) explicita suas linhas de pesquisa e uma das citadas é "O ensino de conhecimentos específicos: literatura, geografia, matemática, alfabetização". No documento da Faculdade de Educação da USP (2012) encontramos referência aos laboratórios de pesquisa e extensão, um dos laboratórios citados explicita a Geografia Escolar como uma possibilidade para campo de investigação.

O envolvimento e a colaboração com o desenvolvimento de pesquisas, durante a formação inicial, pode proporcionar ao graduando uma bagagem teórica e reflexiva. Muitas das IES estudadas apontam que ao final dos estágios solicitam, como estratégia de avaliação, a construção de relatórios. Ao produzirem relatórios sobre as práticas de estágios desenvolvidas, os estudantes têm a oportunidade de revisitar os momentos em sala de aula, com um olhar crítico e reflexivo. Esta pode ser uma maneira de demonstrar ao estudante que a leitura reflexiva sobre a própria prática é fundamental para o trabalho docente.

\section{CONSIDERAÇÕES FINAIS}

Neste artigo apresentamos como os componentes curriculares, voltados para o ensino de Geografia, vêm sendo propostos no currículo formal dos cursos de Pedagogia, das IES públicas estaduais paulistas. Identificamos a presença do ensino de Geografia por meio das

\begin{tabular}{l|c|c|c|c|c|c} 
() Rev. Educ. Perspec. & Viçosa, $M G$ & v. & n.3 & p.462-477 & set./dez. 2017 & eISSN 2178-8359 \\
\hline
\end{tabular}


propostas de estágios supervisionados, das linhas de pesquisa, dos laboratórios de estudos e dos conteúdos a serem trabalhados no Ensino Fundamental.

A variedade apresentada nas cargas horárias dos componentes curriculares estudados demonstra instabilidades e incertezas em relação à referida área do conhecimento. Precisamos superar tais inconsistências, pois é necessário que o ensino de Geografia esteja presente de forma consistente nos cursos de Pedagogia. Com tal formação, o futuro professor poderá desenvolver práticas educativas que envolvam a Geografia, de forma contextualizada e contemplando a localidade do aluno.

A Cartografia Escolar foi mencionada em todas as instituições investigadas. Ressaltamos que, o desenvolvimento da linguagem cartográfica, pode ser fundamental para a superação das práticas educativas mecânicas e descontextualizadas. Tais práticas podem colaborar para que o estudante compreenda a realidade de maneira ampla.

Neste artigo, apontamos que os cursos de Licenciatura Plena em Pedagogia, no âmbito do currículo formal, contemplam o ensino de Geografia, de diferentes maneiras, em diversos momentos e com variadas denominações, portanto, seu "lugar" é garantido, mesmo que minimante, no currículo formal da formação docente. Tais cursos formam os pedagogos que poderão atuar nos anos iniciais do Ensino Fundamental. Consideramos que nesta etapa de ensino é imprescindível que os conhecimentos geográficos sejam desenvolvidos, pois tais conhecimentos são fundamentais para que o estudante construa uma ampla leitura e compreensão de mundo.

\section{REFERÊNCIAS}

ALMEIDA, Rosângela Doin. A propósito da questão teórica metodológica sobre o ensino de geografia. In: RIBEIRO, Wagner Costa (Org.). Prática de ensino em Geografia. São Paulo: Ed. Marco Zero/AGB, 1991.

ALMEIDA, Rosangela Doin de; PASSINI, Elza Yazuko. O espaço geográfico: ensino e representação. 7. ed. São Paulo: Contexto, 1999.

LÜDKE, Menga; ANDRÉ, Marli Eliza Dalmazo Afonso de. Pesquisa em educação: abordagens qualitativas. São Paulo: Pedagógica e Universitária, 1986.

BRASIL. Secretaria de Educação Fundamental. Parâmetros Curriculares Nacionais: História e Geografia $1^{\circ}$ e $2^{\circ}$ Ciclos do Ensino Fundamental. Brasília: MEC/SEF, 1997.

BRASIL. Lei n. 12.796 4 de abril de 2013. Altera a Lei n-9.394, de 20 de dezembro de 1996, que estabelece as diretrizes e bases da educação nacional, para dispor sobre a formação dos profissionais da educação e dar outras providências. 2013. Disponível em:

\begin{tabular}{l|l|l|l|l|l|l} 
() Rev. Educ. Perspec. & Viçosa, $M G$ & v. & n.3 & p.462-477 & set./dez. 2017 & eISSN 2178-8359 \\
\hline
\end{tabular}


<http://www.planalto.gov.br/ccivil_03/_Ato2011-2014/2013/Lei/L12796.htm>. Acesso em: 12 fev. 2017.

CALLAI, Helena Copetti. Aprendendo a ler o mundo: a Geografia nos anos iniciais do Ensino Fundamental. Cadernos Cedes. Campinas, v. 25, n. 66, maio/ago. 2005.

CALLAI, Helena Copetti (Org.). Educação Geográfica Reflexão e Prática. Ijuí: Ed. Unijuí, 2011.

CASTELLAR, Sônia Maria Vanzella A cartografia e a construção do conhecimento escolar. In: ALMEIDA Rosângela Doin (Org.) Novos rumos da cartografia escolar. São Paulo: Contexto, p. 121- 136, 2011.

CAVALCANTI, Lana de Souza. Geografia, escola e construção de conhecimentos. Campinas-SP: Papirus, 1998.

CAVALCANTI, Lana de Souza. A geografia e a realidade escolar contemporânea: avanços, caminhos, alternativas. In: Anais do I Seminário Nacional: currículo em movimento Perspectivas atuais, Belo Horizonte, p. 1-16, 2010.

GARRUTI, Erika Aparecida; SANTOS, Simone Regina. A interdisciplinaridade como forma de superar a fragmentação do conhecimento. Revista de Iniciação Científica, FFC Campus de Marília - São Paulo, v. 4, n. 2, p. 1-11, 2004.

GUIMARÃES, Iara. Possibilidades criativas no ensino de Geografia: diferentes registros e linguagens na sala de aula. In: FONSECA, Selma Guimarães. Ensino fundamental conteúdos, metodologias e práticas. Campinas, SP: ed. Alínea, p. 313-334, 2009.

LAMPERT, Rodrigo Alves. O estudo do lugar como formação do conhecimento e a prática docente em Geografia. In: TONINI, Ivaine Maria; KAERCHER, Nestor André; HOLGADO, Flávio Lopes (Orgs.). Ensino da Geografia e da História: saberes e fazeres na contemporaneidade. Ed 1. Porto Alegre: Evangraf, p. 133-148, 2013.

LASTÓRIA, Andrea Coelho; MELLO, Rafael Cardoso. "Cotidiano" e "Lugar": categorias teóricas da história e da geografia escolar. Universitas: Fernandópolis, v. 4, n. 1, p. 27-34, 2008.

LIBÂNEO, José Carlos. Ensinar e Aprender, aprender e ensinar - O lugar da teoria e da prática em didática. In: LIBÂNEO, José Carlos; ALVES, Nilda (Orgs.) Temas de Pedagogia - Diálogos entre didática e currículo. São Paulo: Cortez, 2012.

MARTINELLI, Marcello. Gráficos e mapas: construa-os você mesmo. São Paulo: Editora Moderna, 1998.

OLIVEIRA, Adriano Rodrigo. Construir uma Didática da Geografia e Cartografia: entre linguagem cartográfica, cultura, saberes e práticas docentes. In: CALLAI, Helena Copetti. Educação Geográfica: reflexão e práticas. Ijuí: Ed. Unijuí, 2011.

\begin{tabular}{l|c|c|c|c|c|c} 
() Rev. Educ. Perspec. & Viçosa, $M G$ & v. & n.3 & p.462-477 & set./dez. 2017 & eISSN 2178-8359 \\
\hline
\end{tabular}


PIMENTA, Selma Garrido; LIMA, Maria Socorro Lucena. Estágio e Docência. 6. Ed. São Paulo: Cortez, 2011.

PONTUSCHKA, Nídia Nacib; PAGANELLI, Tomoko Iyda; CACETE, Núria Hanglei. Para ensinar e aprender Geografia. 3. ed. São Paulo: Cortez, 2009.

SACRISTÁN, José Gimeno. O currículo: uma reflexão sobre a prática. 3. ed. Tradução de Ernani F. da Fonseca. Porto Alegre: Artmed, 1998.

SILVA, Fernanda Keila Marinho; LASTÓRIA, Andrea Coelho. O estágio supervisionado em Ciências, Geografia e História nos anos iniciais: entre o ideal e o real, In: PACÍFICO, Soraya Maria Romano; ARAÚJO, Elaine Sampaio (Orgs.) O estágio e a produção do conhecimento docente. São Carlos: Pedro \&João Editores, 2013.

STACCIARINI, Jeanne Marie R.; ESPERIDIÃO, Elizabeth. Repensando estratégias de ensino no processo de aprendizagem. Revista latino americana de enfermagem. Ribeirão Preto, v. 7, n. 5, p. 59-66, dez. 1999.

STRAFORINI, Rafael. Ensinar geografia: o desafio da totalidade-mundo nas séries iniciais. São Paulo: Annablume, 2004.

UNIVERSIDADE DE SÃO PAUlO, Faculdade de Educação. Projeto Político Pedagógico do curso de Licenciatura em Pedagogia, São Paulo, 2012.

UNIVERSIDADE DE SÃO PAULO, Faculdade de Filosofia, Ciências e Letras de Ribeirão Preto. Projeto Político Pedagógico do curso de Licenciatura em Pedagogia. Ribeirão Preto, 2013.

UNIVERSIDADE ESTADUAL DE CAMPINAS, Faculdade de Educação. Projeto Político Pedagógico do curso de Licenciatura em Pedagogia. Campinas, 2015.

UNIVERSIDADE ESTADUAL PAULISTA "JÚLIO DE MESQUITA FILHO", Faculdade de Ciências. Projeto Político Pedagógico do curso de Licenciatura em Pedagogia. Bauru, 2006.

UNIVERSIDADE ESTADUAL PAULISTA "JÚLIO DE MESQUITA FILHO", Faculdade de Filosofia e Ciências. Projeto Político Pedagógico do curso de Licenciatura em Pedagogia. Marília, 2007.

UNIVERSIDADE ESTADUAL PAULISTA "JÚLIO DE MESQUITA FILHO", Instituto de Biociências, Letras de Ciências Exatas. Projeto Político Pedagógico do curso de Licenciatura em Pedagogia. São José do Rio Preto, 2008.

UNIVERSIDADE ESTADUAL PAULISTA "JÚLIO DE MESQUITA FILHO", Instituto de Biociências. Projeto Político Pedagógico do curso de Licenciatura em Pedagogia. Rio Claro, 2011.

\begin{tabular}{l|l|l|l|l|l|l} 
(C) Rev. Educ. Perspec. & Viçosa, $M G$ & v. & n.3 & p.462-477 & set./dez. 2017 & eISSN 2178-8359 \\
\hline
\end{tabular}


UNIVERSIDADE ESTADUAL PAULISTA "JÚLIO DE MESQUITA FILHO", Faculdade de Ciências e Tecnologia. Projeto Político Pedagógico do curso de Licenciatura em Pedagogia. Presidente Prudente, 2011.

UNIVERSIDADE ESTADUAL PAULISTA "JÚLIO DE MESQUITA FILHO", Faculdade de Ciências e Letras de Araraquara. Projeto Político Pedagógico do curso de Licenciatura em Pedagogia. Araraquara, 2015.

\title{
NOTAS
}

\begin{abstract}
${ }^{i}$ A Lei n. ${ }^{\circ}$ 12.796, de 4 de abril de 2013, em seu Artigo 62, estabelece que é admitida, no Brasil, a formação em nível médio na modalidade normal: "A formação de docentes para atuar na educação básica far-se-á em nível superior, em curso de licenciatura, de graduação plena, em universidades e institutos superiores de educação, admitida, como formação mínima para o exercício do magistério na educação infantil e nos 5 (cinco) primeiros anos do ensino fundamental, a oferecida em nível médio na modalidade normal" (BRASIL, 2013).

${ }^{i}$ Ao longo de todo o artigo citamos dados referentes aos Projetos Políticos Pedagógicos que foram produzidos pelos cursos de Pedagogia das seguintes instituições, nos determinados anos, Faculdade de Educação UNICAMP no ano de 2015, Faculdade de Educação - USP no ano de 2012, Faculdade de Filosofia Ciências e Letras de Ribeirão Preto - USP, 2013; Faculdade de Ciências - UNESP/Bauru, 2006; Instituto de Biociências, Letras e Ciências Exatas - UNESP/São José do Rio Preto, 2008; Faculdade de Ciências e Letras de Araraquara. - UNESP/Araraquara, 2015; Instituto de Biociências - UNESP/Rio Claro, 2011; Faculdade de Ciências e Tecnologia - UNESP/Presidente Prudente, 2011; Faculdade de Filosofia e Ciências - UNESP/Marília, 2007. Os documentos são os vigentes no ano de 2016.
\end{abstract}

\section{Sobre as Autoras}

${ }^{1}$ Thais Angela Cavalheiro Azevedo - Licenciada em Pedagogia e Mestre em Educação pela Faculdade de Filosofia, Ciências e Letras de Ribeirão Preto - FFCLRP, na Universidade de São Paulo - USP. Pedagoga do Centro Infantil Boldrini. E-mail: thais.deazevedo@ hotmail.com ORCID: http://orcid.org/0000-0002-0672-1920

${ }^{2}$ Andrea Coelho Lastória - Licenciada em Geografia e Pedagogia. Bacharel em Geografia. Mestre e Doutora em Educação pela Universidade Federal de São Carlos - UFSCar. Pósdoutorado em Didática da Geografia e História pela Universidade de Oviedo, Espanha. Professora do Programa de Pós-Graduação em Educação e do Curso de Pedagogia na Faculdade de Filosofia, Ciências e Letras de Ribeirão Preto - FFCLRP, da Universidade de São Paulo - USP. E-mail: lastoria@ffclrp.usp.br - ORCID: http://orcid.org/0000-0002-0060-0116

${ }^{3}$ Filomena Elaine Paiva Assolini - Licenciada em Pedagogia e Letras. Mestre e Doutora em Psicologia pela Universidade de São Paulo. Professora do Programa de Pós-Graduação em Educação e do Curso de Pedagogia na Faculdade de Filosofia, Ciências e Letras de Ribeirão Preto - FFCLRP, da Universidade de São Paulo - USP. E-mail elainefdoc@ffclrp.usp.br ORCID: http://orcid.org/0000-0002-8433-4862 